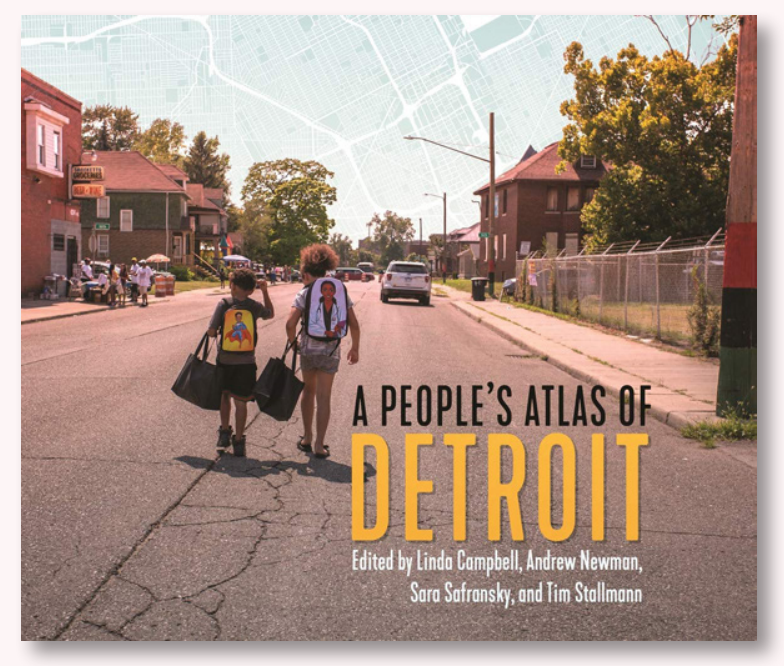

\section{A PEOPLE'S ATLAS OF DETROIT}

Edited by Linda Campbell, Andrew Newman, Sara Safransky and Tim Stallman

Wayne State University Press, 2020

352 pages

Paperback: \$34.99, ISBN 978-0-8143-4297-8

eBook: \$24.99, ISBN 978-0-8143-4298-5

Review by: Russell S. Kirby, University of South Florida
The editors of $A$ People's Atlas of Detroit have produced a book that is spot-on for these troubled times. It's hard to imagine that they had the prescience to anticipate George Floyd's murder, the resurgence of the Black Lives Matter movement, and the broad national focus on structural racism that has emerged in this past year; yet that, in broad strokes, is the focus of their work. They have produced an interesting book, with an impressive pedigree and purpose that extends well beyond the primarily academic focus of most atlases. So well beyond, in fact, that many readers will take issue with calling it an atlas (a term typically defined as a book of maps or charts), as very few of its pages are devoted to maps, and many of those are used solely to designate the locations of those who contributed content to specific chapters.

A People's Atlas of Detroit unabashedly follows in the footsteps of William Bunge's legendary Fitzgerald: Geography of a Revolution (originally published in 1971 and now available in a 2011 softbound edition by University of Georgia Press). Both books call attention to the social geography of the Detroit metropolitan area through the lens of social justice, and both examine the spatial structures of commerce, social capital, amenities, and other resources with a focus on lived experiences, and personal and community histories. However, A People's Atlas of Detroit is much more personal, and conveys those experiences through numerous vignettes, interviews, and reflections from residents of disadvantaged neighborhoods throughout the city.
The book consists of six chapters and an epilogue. The first chapter provides historical context, with vignettes examining the history of slavery in Detroit; the Underground Railroad and resistance to slavery before the Civil War; labor struggles; conflict over housing; local events in the Civil Rights movement of the 1960s; and the uprisings in the summer of 1967 . The chapter concludes with a reflective conversation between Grace Lee Boggs, a prominent community activist, and Sterling Toles.

Chapter 2 focuses on land ownership and the notion of community. At the outset, the authors seek to dispel the myth that Michigan's vacancy rates for residential housing are highest within the City of Detroit. Using data from the American Community Survey, a map creatively shows the names and approximate locations of other cities in the state with rates higher than the $28 \%$ reported for Detroit in 2008-2012. The chapter also explores patterns of land ownership, the physical divide of the river that forms an international border between the US and Canadian sections of a metropolitan region with numerous economic, social, and cultural ties, as well as how structural racism has affected disadvantaged communities through discriminatory practices related to freeway construction, urban "renewal," and redlining. This chapter also includes several vignettes, focusing on urban gardening and fishing as ways to connect community residents to the land they share. The chapter concludes with a poignant interview with Michelle Martinez, a woman of Mexican, 
Colombian, and Native American heritage who suggests the need for "a plan that honors people in this place, on this land" (111).

Chapter 3, "Growing a Revolution," focuses on opportunities for transformation in urban Detroit. Much of the emphasis is on the potentially transformative role of urban agriculture, not only as a source for food in a region with endemic food insecurity, but also as a source of economic livelihood, a way to reclaim inner-city neighborhoods and industrial districts lost in the global transition of heavy manufacturing from North America to less developed economies, and for its potential role in promoting Black self-reliance and transformation. This chapter consists largely of narratives and interviews, but also includes a brief cartographic essay illustrating some aspects of the history of urban agriculture in Detroit.

In Chapter 4, "Suspending Democracy is Violence," the authors focus on both the context for, and effects of, political and economic reform in Michigan generally and more specifically in the Detroit metropolitan area. The financial challenges of majority-Black Detroit are reflected in numerous communities across Michigan, many of which (such as Flint) have suffered the devastating consequences of poor decisions about municipal economics. The chapter details numerous actions taken for the ostensible purpose of cost-savings that have adversely affected Black residents of Detroit and describes community advocacy efforts to provide a larger voice for disadvantaged populations.

Race and the geography of displacement is the focus of the fifth chapter. As with issues explored in previous chapters, the authors demonstrate that gentrification is the visible face of much more complex social and economic processes at play in inner-city Detroit. The chapter explores spatial patterns of Black homeownership compared to Asian and Hispanic homeownership since 1960, and levels of housing insecurity in Detroit and other urban communities across the United States. Displacement effects of urban renewal are illustrated through a historical example from the Detroit Geographical Expedition and Institute. Discriminatory policies related to housing are described both graphically and in narrative form. The authors argue in favor of a broader-based approach to urban revitalization, one that incorporates the needs and aspirations of all Detroit's citizens, and illustrate this approach with vignettes describing several specific community-based efforts.
The final chapter is "The Right to the City." The authors provide a vision for the future, emphasizing five themes embodying the rights to: water, environmental justice, mobility, education, and freedom from crime and police harassment. Water shutoffs, for example, adversely affect the disadvantaged, and community-based efforts to prevent shutoffs and support those in danger of losing their water supplies are described in this chapter. Environmental racism is illustrated through an examination of the spatial distribution of asthma hospitalizations in the Detroit metropolitan region, while policies for expanding public transit are explored through a vignette describing plans to implement streetcar service on a main bus route. An interesting map displays the proportion of residents incarcerated per 1,000 population, accompanied by a map showing the locations of state prisons and the numbers of Detroit residents incarcerated in each. Not surprisingly, most of these prisons are located at considerable distances from the city, and visitation by family members is challenging. In the conclusion to the atlas, the authors argue that "Another city is possible" (296), and that making it so will require changing the structures of economic and political power, community engagement, activism, and both internal and external support.

Having briefly described the contents of A People's Atlas of Detroit, one can see that this is by no means a typical contribution either to the genre of atlases or to the field of urban geography. Like most atlases, the book does contain numerous maps, along with statistical graphics and photographs both in color and black and white, but while most atlases array maps around specific themes, here each map was carefully selected to illustrate specific points in the authors' narrative concerning the lived experiences of disadvantaged Detroit residents and their vision for a very different future from what may evolve if current policies and spatial dynamics persist. The narratives and interviews included with each chapter have poignancy and salience, but it is likely that the authors could have expressed the same sentiments and views in a more focused manner, or have captured a broader sense of the needs and challenges Detroit citizens face using more formal analytical methods with qualitative study designs.

This atlas was intended to open the eyes of readers to the past, the present, and the possible. From a pedagogical perspective, courses in social or urban geography might use this book to contrast with more conventional geographical and social science research on Detroit. Sociologists and 
anthropologists will find much of interest within these pages. Cartographers might explore themes introduced in this atlas in more depth, and consider methods for mapping spatial patterns and processes indicative of structural racism. Many communities across the United States have histories that are similarly worthy of this type of in-depth exploration.

As with its predecessor, Fitzgerald: Geography of a Revolution, A People's Atlas of Detroit marks not an endpoint, but a summation of collective work to date in documenting the major structural changes needed to improve the lives of the residents of Detroit. By promoting politics and practices that serve the needs of all, we can ensure that everyone is accorded basic rights in a meaningful way. Although the authors do not use the term explicitly, structural racism lies at the core of Detroit's problems, and must be disentangled persistently and systematically. A People's Atlas of Detroit makes this point extremely well, and it should be read by those interested in gaining a sense not only of the challenges that must be overcome, but what is at stake if we fail. 